\title{
Analysis of Photovoltaic Power Generation for Electric Vehicle Application
}

\author{
Merlin Suba $\mathrm{G}^{\mathrm{a}, 1}$, and Kumaresan $\mathrm{M}^{\mathrm{b}}$ \\ ${ }^{a}$ Research scholar, Dept of EEE, Dr.M.G.R Educational and Research Institute \\ University, Chennai \\ ${ }^{b}$ Professor, Dept of ECE, Dr.M.G.R Educational and Research Institute University, \\ Chennai
}

\begin{abstract}
This paper presents a hybrid solar- energy supply with battery storage for electric vehicle applications. This converter is designed to improve the topologies of the Cuk-Boost converter in parallel power transfer mode to achieve higher performance. Extract maximum energy from the hybrid PV source simultaneously. Hybrid source fed Cuk -Boost converter performance is analyzed in this paper using MATLAB/SIMULINK. To achieve maximum output voltage, while using proposed scheme compared to existing converters topologies.
\end{abstract}

Keywords: DC-DC converters, Maximum power point tracking (MPPT), Parallel power transfer mode and Photovoltaic system.

\section{Introduction}

Electricity demand has increased considerable over the past few years due to the rapid growth in populations and economies. The global demand for electric energy is expected to double by the year 2050,varying based on economic growth. In the last decade ,there has been renewed interest in key uses of renewable energy sources and power electronic systems to capitalize on such energies. Renewable Energy Sources(RES) includes wind energy, photovoltaic(PV)energy, and hydro energy, greenhouse gas emissions such as carbon dioxide $(\mathrm{CO} 2)$.As a result, the penetration of renewable energy power generators should be increased, considering total power system security and reliability. Among many renewable resources, solar energy is essential one because of its sustainability and advanced technologies. Many sources are used to provide a continuous power supply to the load. The load is receiving the power from the source and can utilize simultaneously. Various energy sources required for future power systems. Multi-input power conversion system can use for practical development to enable multi-source technology. To increase the reliability and utilization of sustainable sources, the power source is diversified with multiple inputs.

Usually, solar, fuel cell and wind power sources are combined as a hybrid renewable energy system(HRES).The hybrid system energy that can be renewed and it is achieving reliability improvement. Also, wind energy sources are complementary , and the battery size can be reduced as the solar system [1-3].In addition, DC bus voltage and the required harmonic and switching noise suppression filters can be 
converted into the ac voltage for grid connection [4]. The generated power using wind and PV are can be sent to grid[5,6,7].For hybrid wind/solar energy systems, a new multi-input Cuk-SEPIC rectifier stage is used,and the features are to filter our highfrequency harmonics additional input filters are not necessary ,step up/ down process can be done by both renewable sources(suitable wide ranges of supply from both PV and wind)[8].Moreover, the mathematical models and simulation tools are needed for design optimization solar power systems. Moreover, in this proposed system is designed to power flow control in the converter. MPPT based PWM control is utilized to extract maximum power and low current ripple from PV modules. The usage of PPT technique for Cuk-SEPIC converter is used in the telecom power supply. The solar charger controller application based PPT configuration for dynamic analysis is obtained as well as the design of the Cuk converter is presented[15] .

In this paper ,a high gain Cuk -Boost converter used in the proposed hybrid solar system which is applied for electric vehicle applications.Because the inherent nature of this Cuk-Boost connected converter is that additional input filters are not necessary to filter out high-frequency harmonics. The solar ource supply and the energy sources availability are essential ones due to the load depending it simultaneously or separately.The MPPT technique can extract solar system power.Astandard incremental conductance MPPT power technique is used in the solar system.

\section{Operating Principle of Solar Cell}

The main and common components of the PV systems are a charge-discharge controller,computer control, energy storage system and auxiliary power generation system. The energy generation of PV array is represented in figure 1.

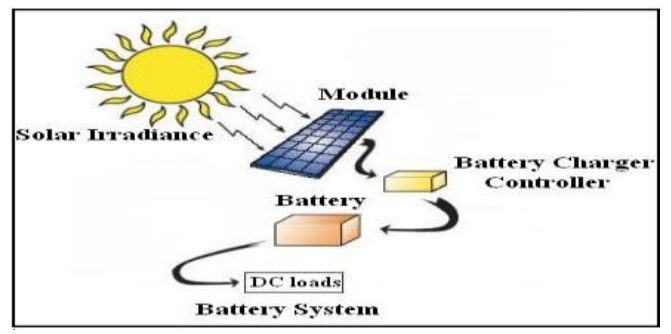

Figure 1. PV Energy Generation

Photovoltaic systems can provide clean energy for small or large utilities.Pv system can be classified into two types:standalone and grid connected mode.Standalone PVsystems are installed in isolated locations and operated independently of the utility grid.They are off-grid system and it is equipped with battery. They can supply DC or AC loads with considering different control systems.

To get a sufficient voltage and current, a group of series and parallel PV modules should be connected, representing a photovoltaic array.The size of a PV array depends on the number of PV modules which are connected in a given PV system.If the irradiation of $\mathrm{PV}$,then the battery is required to supply power to DC load under the control of the controller.

V-I characteristic of PV module is given below, 


$$
I=I i_{i}-I_{o}\left(e^{\frac{q\left(V+I R_{S}\right)}{n k t}}-1\right)
$$

Where $I_{i}=$ PVpanel current, $I_{0}=$ saturation current of diode, $R_{S}=$ shunt resistance, $\mathrm{K}=$ constant, $\mathrm{T}=$ Temperature a

nd $n=$ number of PV module, $v=$ solar cell voltage

\section{Modeling of Solar Array}

This section provide single diode model of the pv cell and its equivalent circuit model includes the series and parallel resistance.The single diode model solar arry is illustrated in figure2.

$$
I=I_{p v, \text { cell }}-I_{o, \text { cell }}\left[\exp \left(\frac{q v}{\alpha k T}\right)-1\right] I_{d}
$$

Where Ipv,cell=current generated by incident light,Io,cell=reverse saturation current of $\mathrm{pv}$ cell, $\mathrm{q}=$ electron charge $=\left[1.60217646 .10^{-19} \mathrm{C}\right], \mathrm{k}=$ Boltzmann constant $\left[1.3806503 .10^{-23} \mathrm{~J} / K\right], \mathrm{T}=$ temperature

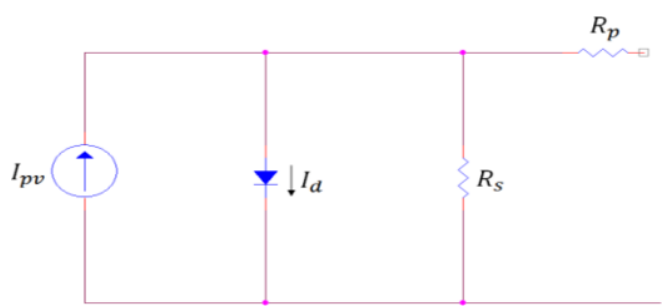

Figure 2. Single diode, series and parallel resistance equivalent circuit diagram

$$
I=I_{p v}-I_{O}\left[\exp \left(\frac{V+R_{s} I}{V_{t}}\right)-1\right]-\frac{V+R_{s} I}{R_{p}}
$$

$I_{p v}=I_{p v, c e l l} N_{p}, I_{0}=I_{0, \text { cell }} N_{p}$. The light-generated current of the PV (photo voltaic) cell depends linearly on irradiation and Temperature influenced by solar equation expressed as,

$$
I_{p v}=\left(I_{p v, n}+K_{I}+\Delta_{T}\right) \frac{G}{G_{n}}
$$

Where Ipv is generated light current at nominal condition $\left(25^{\circ} \mathrm{C}\right.$ and $\left.1000 \mathrm{~W} / \mathrm{m} 2\right), \Delta_{T}=$ $T-T_{n}(\mathrm{~T}$ and $\mathrm{Tn}$ is the actual and nominal current at nominal current temperature(k), $\mathrm{G}(\mathrm{W} / \mathrm{m} 2)$ is the irradiation on the device surface and $\mathrm{Gn}$ is the nominal irradiation. The diode saturation current Io by temperature is given by, 


$$
I_{o}=I_{O, n}\left(\frac{T_{n}}{T}\right)^{3} \exp \left[\frac{V E_{g}}{\alpha k}\left[\frac{1}{T_{n}}-\frac{1}{T}\right]\right]
$$

\section{Proposed Photovoltaic Source Cuk - Boost Converter}

A proposed two input source fed converer system is shown in Figure 3.where the positive terminal of two input source is connected with proposed converter and negative terminal of the input sources are connected with each source which is achieved by reconfiguring the two forward diodes from each converter.

The configuration of cuk -boost converter input sources makes it possible for each converter in the circuit to work individually as well as for a single source. The source1 is available means D1 is ON,and D2turns off,and the circuit becomes a Cuk converter.Input/output voltage gain relationship of the cuk-boost converter is given in the below equation.

$$
\frac{V_{d c}}{V_{p v 1}}=\frac{d_{1}}{1-d_{1}} \text { and } \frac{V_{d c}}{V_{p v 2}}=\frac{1}{1-d_{2}}
$$

In the both cases, the input to output voltage relationship is given below by equation

$$
V_{d c}=\left(\frac{d_{1}}{1-d_{1}}\right) V_{p v 1}+V\left(\frac{1}{1-d_{2}}\right) V_{p v 2}
$$

In this case,both converters cuk and DC-DC boost converter(BC) is contained the capacity of step-up/down, if the duty cycle ratio of the converter control is used to increase the reliability and it provides more flexibility to the system. The proposed hybrid system of Cuk-boost converter is shown below in figure 3 .

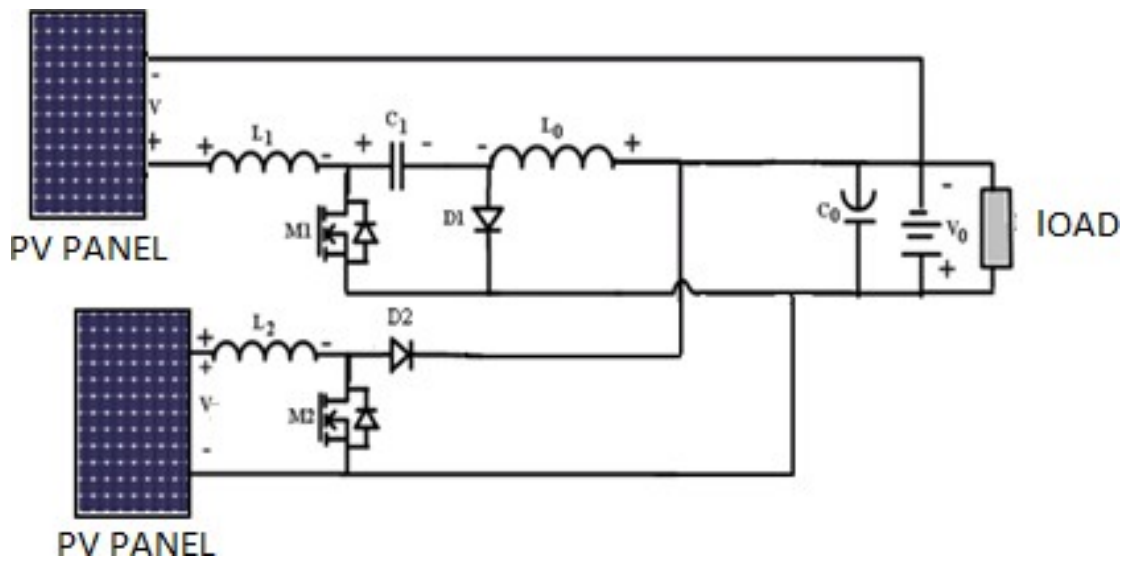

Figure 3. Circuit diagram of the hybrid system

The proposed model consists of an arrangement of cuk and Boost converters which increase the Vo.Utilization of converter output current. MPPT technique is used to step up/step down the input voltage from PV.

The arrangement of the proposed converter topology reduces the component counts.So that inductor(Lo) and filtering capacitor(Co) is common for both converter 
output side. High voltage gain and efficiency can be achieved by connecting the cukboost converter in parallel to each converter. Due to this configuration, high voltae gain can be extracted from the input source $(\mathrm{PV})$.

\section{Simulation Results}

The proposed hybrid system of Cuk - Boost converter configuration is implemented and results are verified in MATLAB/SIMULINK also analysis performance of the converter, this simulation based study is carried out.The system parameter is taken the same as conventional topologies of cuk-SEPIC converter. Cuk-SEPIC topologies.

Therefore, the simulink model results provide the presentation of hybrid cuk boost converter system , and its advantages are high efficiency, requiring smaller size and lower switching devices. Figure 4 represents the simulink model of two input sources based hybrid converter system.

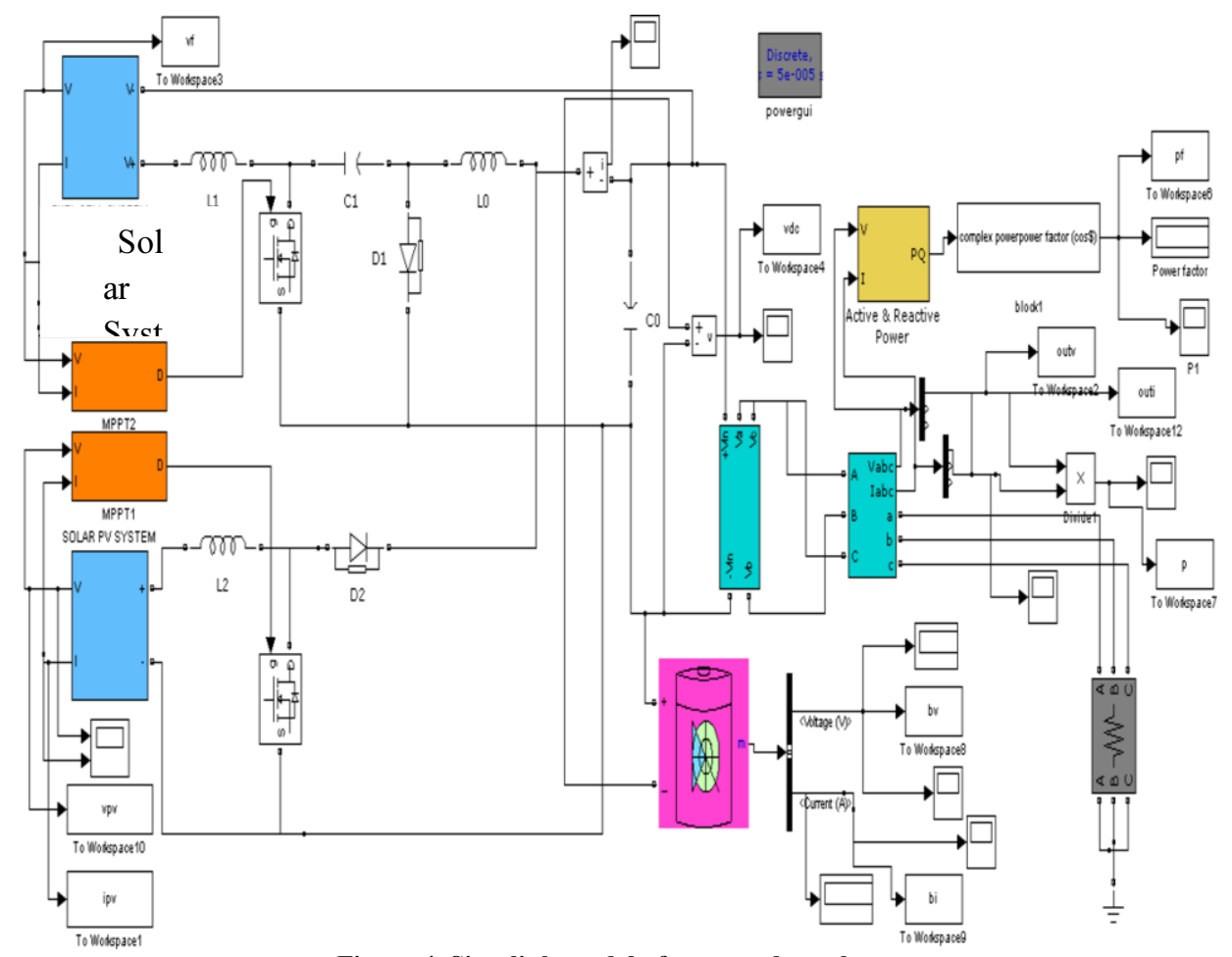

Figure 4. Simulink model of proposed topology

The resistor is considered as the load considered for this simulation process. Figure 5 represents the single diode model of the PV module has been implemented using MATLAB/ simulink . PV output is varied dynamically because of the conditions of radiation and irradiation.Solar system output is shown in figure 6 as voltage and current . 

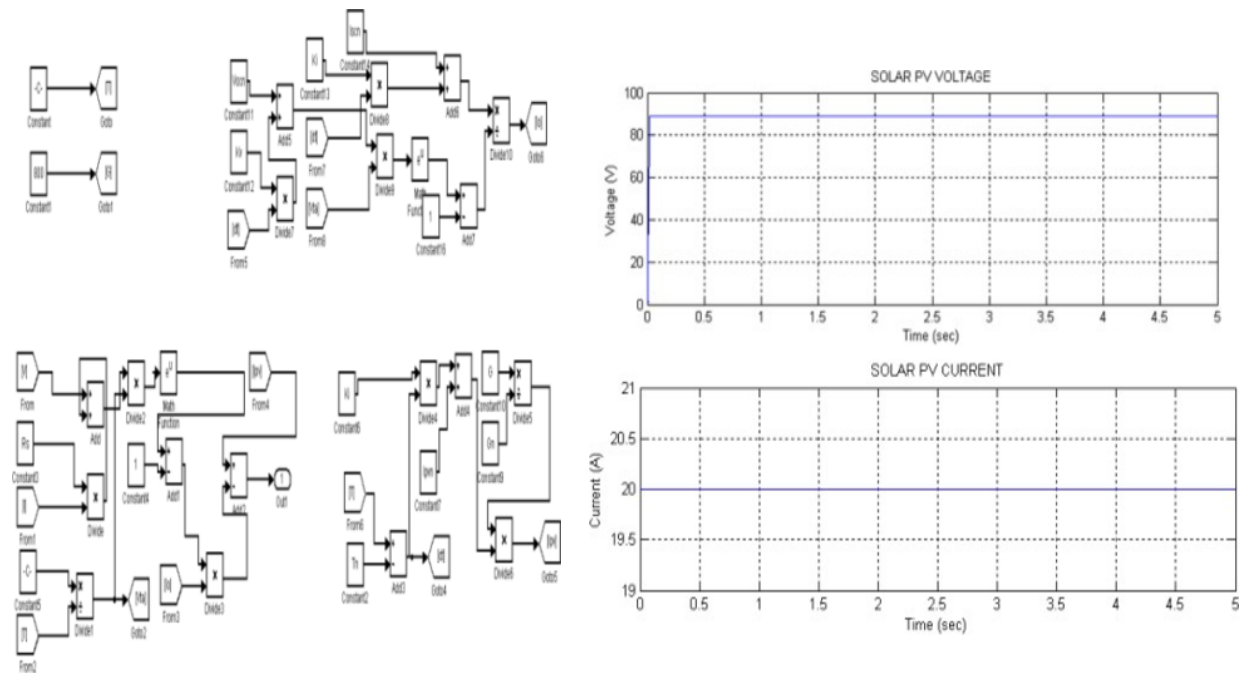

Figure 5. Simulink Block for solar photovoltaic system

Figure 6. Solar PV system voltage and current waveform

The power obtained from the proposed converter shows its maximum extracting capacity, and it is continuously working near the maximum operating point of solar cells. The simulink modeling MPPT is shown in figure 7.

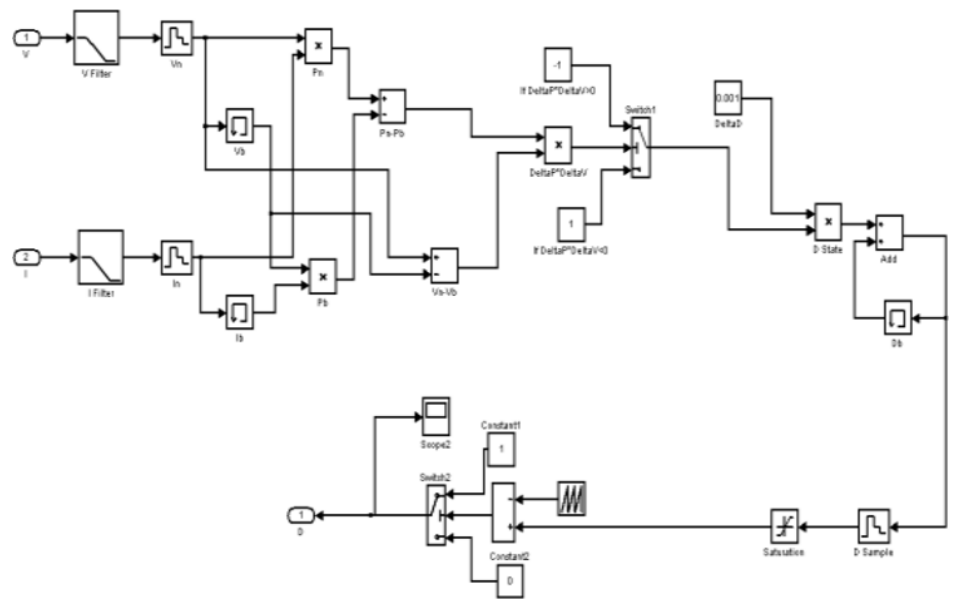

Figure 7. Simulink Block of incremental conductance MPPT model

The two converter hybrid system is reached by the connection of each converter with two exciting diodes and the mutual use of the cucumbers by the boost converter.The DC voltage of the Cuk-boost converter shown in figure 8. 
This proposed configuration with $\mathrm{R}$ load of the output boosted voltage $350 \mathrm{~V}$ can be obtained. The input of the Cuk is $96 \mathrm{~V}$ and the input of Boost is $89 \mathrm{~V}$ from the solar PV system. The output voltage and current waveform for proposed scheme using without and with filter is shown below in figure 9, 10.

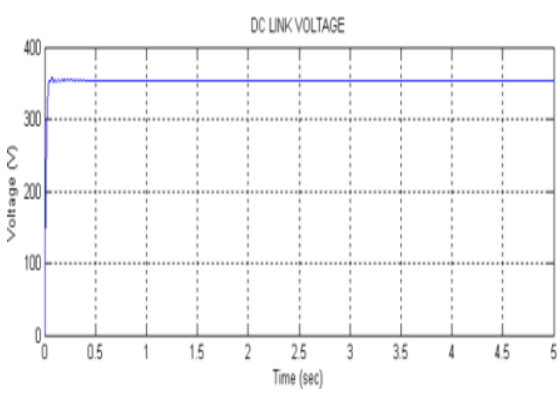

Figure 8. DC link voltage waveform

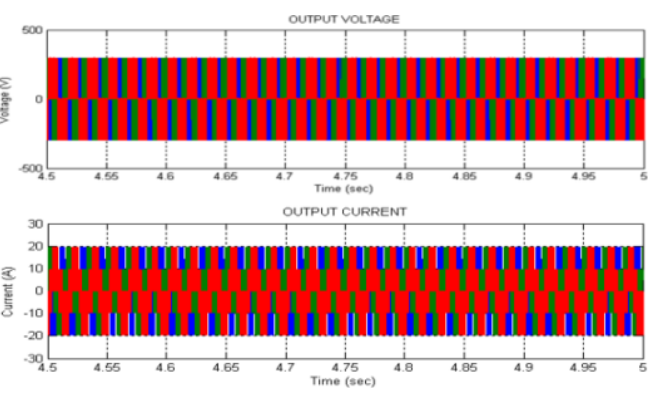

Figure 9. The waveform of output voltage and current without filter

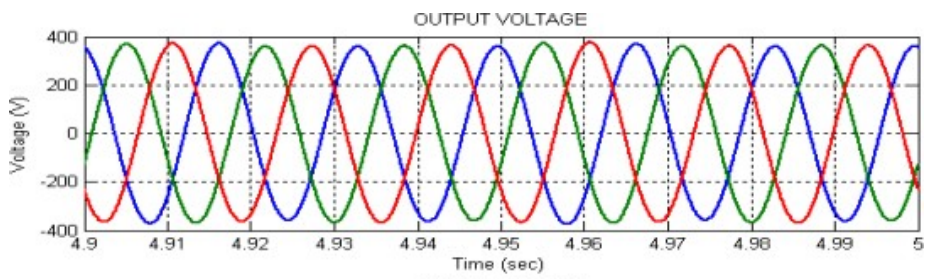

OUTPUT CURRENT

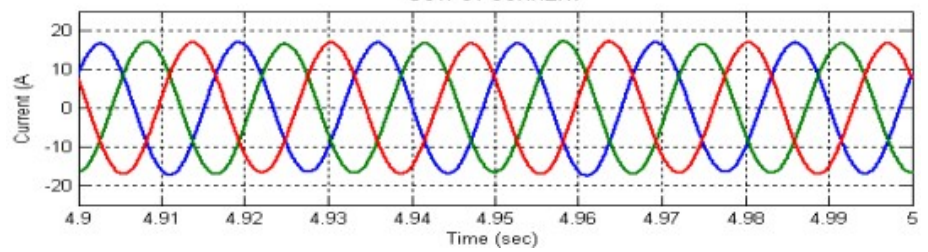

Figure 10. The waveform of output voltage and current with filter

\section{Conclusion}

The performance of renewable energy sources has been analyzed with converters for electric vehicle applications. The high output voltage gain is obtained from the hybrid input supply system. The cuk-boost converter is used to reduce the voltage stress(V) and current(I) stress and also achieve higher efficiency by using power transfer techniques. Moreover, additional advantages of this proposed topology using for the reduced component count and does not require input filters for high harmonics which presents in the system. Hence, the dynamic performance of the cuk-boost converter and their simulation results are verified using MATLAB/ Simulink for electric vehicle application wit a low rating of switching devices. 


\section{References}

[1] Hadi Moradisizkoohi,Osama A.Mohammed .Experimental verification of a double input soft switched DC-DC Converter for Fuel cell Electric vehicle Hybrid Energy Storage System .IEEE, vol.55, pp. 6451-6465,.2019

[2] Yan Li, Xinbo Ruan, Dongsheng Yang, Fuxin Liu and Chi K. Tse .Synthesis of Multiple-Input DC/DC Converters. IEEE transactions on power electronics, vol. 25, no. 9, pp. 2372-2385, September 2010.

[3] Alexis Kwasinski and Philip T. Krein .Multiple-input dc-dc converters to enhance local availability in grids using distributed generation resources . IEEE, pp .1657-1663, 2007.

[4] Luca Solero, Alessandro Lidozzi and Jose Antenor Pomilio .Design of Multiple-Input Power Converter for Hybrid Vehicles. IEEE Transactions on power electronics, vol. 20, no. 5, pp. 1007-1016, September 2005.

[5] Omer Caglar Onar, Omid Hajiamin A. Shirazi and Alireza Khaligh .Grid Interaction Operation of a Telecommunications Power System With a Novel Topology for Multiple-Input Buck-Boost Converter. IEEE Transactions on power delivery, vol. 25, no. 4, pp. 2633-2645, October 2010.

[6] Omid Haji Arnin Shirazi, Orner Onar and Alireza Khaligh .A Novel Telecom Power System . IEEE, p8, 2008.

[7] Yaow-Ming Chen, Yuan-Chuan Liu, Shih-Chieh Hung, and Chung-Sheng Cheng .Multi-Input Inverter for Grid-Connected Hybrid PV/Wind Power System . IEEE transactions on power electronics, vol. 22, no. 3, pp. 1070-1077, may 2007.

[8] A.Di Napoli, F. Crescimbini, S. Rodo and L. Solero .Multiple Input DC-DC Power Converter for FuelCell Powered Hybrid Vehicles .IEEE, pp. 1685-1690, 2002.

[9] Joanne Hui, Alireza Bakhshai, and Praveen K. Jain .A Hybrid Wind-Solar Energy System: A New Rectifier Stage Topology .IEEE, pp. 155- 161, 2010.

[10]B. Ambrosio. Cultura and Ziyad M. Salameh. Dynamic Analysis of a Stand Alone Operation of PEM Fuel Cell System. Journal of Power and Energy Engineering, vol. 2, pp. 1-8, 2014.

[11]B. Mangu, K. Kiran Kumar and B. G. Fernandes .Efficiency Improvement of Solar-Wind based DualInput Converter for Telecom Power Supply .IEEE, pp. 1-6, 2012.

[12] J. H. R. Enslin and D. B. Snyman .Combined Low-Cost, High-Efficient Inverter, Peak Power Tracker and Regulator for PV Applications. IEEE transactions on power electronics, vol. 6. No. 1, pp. 73-82, January 1991.

[13]H. Tao, A. Kotsopoulos, J.L. Duarte and M.A.M. Hendrix .Family of multiport bidirectional DC-DC converters .IEE Proc.-Electr. Power Appl., Vol. 153, No. 3, pp. 451-458, May 2006.

[14] Roger Gules, Juliano De Pellegrin Pacheco and Johninson Imhoff, A Maximum Power Point Tracking System With Parallel Connection for PV Stand-Alone Applications .IEEE transactions on industrial electronics, vol. 55, no. 7, pp. 2674-2683, July 2008.

[15] J. A. Gow and C. D. Manning, Development of a photovoltaic array model for use in power-electronics simulation studies .Electric Power Applications, IEE Proceedings, 146(2):193-200, 1999. 